\title{
OPTIMIZATION OF A SEMI-BATCH REACTION SYSTEM UNDER SAFETY CONSTRAINTS
}

\author{
O. Ubrich ${ }^{+}$, B. Srinivasan*, F. Stoessel ${ }^{+}$, D. Bonvin* \\ ${ }^{+}$Novartis Services AG, CH-4002 Basel, Switzerland \\ *Institut d'Automatique, Ecole Polytechnique Fédérale de Lausanne \\ CH-1015, Lausanne, Switzerland \\ *Fax: +41216932574 and e-mail: dominique.bonvin@epfl.ch
}

Keywords: Optimal control, Semi-batch reaction systems, Process optimization, Safety considerations.

\begin{abstract}
Maximizing the yield of a second-order reaction by manipulating the inlet flow rate is considered in both the isoperibolic and isothermal modes. For safety considerations, constraints on (i) the amount of heat produced, and (ii) the temperature under cooling failure are imposed. The optimal solution is discontinuous and is first obtained numerically. Analytical expressions for (i) the evolution of the input between the discontinuities, and (ii) the switching times are obtained. Using the analytical characterization of the optimal solution, an efficient feedback implementation strategy is designed.
\end{abstract}

\section{Introduction}

An important objective in the chemical industry is to find the operating conditions that maximize profit while ensuring safe operation. The safety considerations arise from the exothermic nature of most industrial chemical reactions. For normal operation, the system must be able to remove the heat produced [1]. But at the same time, the system must be capable of withstanding a cooling failure [2]. These goals can be best achieved by working with a semi-batch reactor since the contents of the reactor can be controlled by the external feed.

Two modes of operation are studied in this work: (a) the isoperibolic mode, where the temperature of the cooling fluid is kept constant, and (b) the isothermal mode, where the temperature of the reaction mass is kept constant by adjusting the temperature of the cooling fluid.

The operation of reactors under isoperibolic and isothermal modes is well studied ( $[3,4]$ for isoperibolic mode, [5] for isothermal mode). The optimization aspects are considered in $[6,7]$. The safety aspects under cooling failure are described in [8], though the optimization issues are not considered therein. Abel et al. [9] propose optimization-based approaches to the design of batch reactors upon consideration of operational and safety constraints. Abel and Marquardt [10] present a model predictive scheme for the on-line optimization of strongly exothermic semi-batch reaction systems under explicit safety requirements.

This article discusses the optimisation aspects under safety constraints for a second-order reaction. The objective is to maximise the conversion for a given terminal time. A numerical solution is first obtained using a software tool based on MATLAB $^{\odot}$ [11]. The interpretation of the results leads to a piece-wise analytic characterisation of the solution. A feedback implementation strategy is designed to handle model mismatch and disturbances [12].

The paper is organised as follow. Section 2 formulates the problem, while the numerical solution is discussed in Section 3. The solution is characterised in Section 4 , and Section 5 deals with implementation aspects. Finally, Section 6 concludes the paper.

\section{Problem formulation}

\subsection{Modeling}

The exothermic reaction $\mathrm{A}+\mathrm{B} \rightarrow \mathrm{C}$ in a semi-batch reactor is considered. The reactor is filled initially with $A\left(\mathrm{~N}_{\mathrm{a}}^{\circ}\right.$ moles and volume $\left.\mathrm{V}_{\mathrm{a}}^{\circ}\right) \cdot \mathrm{N}_{\mathrm{b}}^{\circ}$ moles of $\mathrm{B}$ of initial volume $\mathrm{V}_{\mathrm{b}}^{\circ}$ are fed through the inlet at the concentration $c_{b, i n}=N_{b}^{\circ} / V_{b}^{\circ}$.

The number of moles of $\mathrm{A}$ and $\mathrm{B}, \mathrm{N}_{\mathrm{a}}$ and $\mathrm{N}_{\mathrm{b}}$, can be expressed in terms of the molar conversion, $\mathrm{x}_{\mathrm{a}}$, and the volume of the reaction mass, $\mathrm{V}$, as follows:

$$
\begin{aligned}
\mathrm{N}_{\mathrm{a}} & =\mathrm{N}_{\mathrm{a}}^{\circ}\left(1-\mathrm{x}_{\mathrm{a}}\right) \\
\mathrm{N}_{\mathrm{b}} & =\mathrm{N}_{\mathrm{b}}^{\circ}\left(\frac{\mathrm{V}-\mathrm{V}_{\mathrm{a}}^{\circ}}{\mathrm{V}_{\mathrm{b}}^{\circ}}\right)-\mathrm{N}_{\mathrm{a}}^{\circ} \mathrm{x}_{\mathrm{a}}
\end{aligned}
$$

The reaction rate is assumed to obey the power law:

$$
r\left(x_{a}, V, T\right)=\frac{k^{\circ} \exp \left(\frac{-E a}{R T}\right) N_{a} N_{b}}{V^{2}}
$$


where $\mathrm{Ea}$ is the activation energy, $\mathrm{R}$ the gas constant, $\mathrm{T}$ the temperature and $\mathrm{k}^{\circ}$ the rate constant.

Heat is removed by a fluid of temperature $T_{c}$ circulating in a cooling jacket. The heat transfer area is related to the volume of the reaction mass:

$$
\mathrm{A}=\frac{2 \mathrm{~V}}{\sigma}+\pi \sigma^{2}
$$

where $\sigma$ is the radius of the reactor.

Material and energy balances result in the following dynamic model:

$$
\begin{array}{lr}
\dot{\mathrm{X}}_{\mathrm{a}}=\frac{\mathrm{r} \mathrm{V}}{\mathrm{N}_{\mathrm{a}}^{\circ}} & \mathrm{x}_{\mathrm{a}}(0)=0 \\
\dot{\mathrm{V}}=\mathrm{u} & \mathrm{V}(0)=\mathrm{V}_{\mathrm{a}}^{\circ} \\
\dot{\mathrm{T}}=\frac{(-\Delta \mathrm{H})}{\rho \mathrm{c}_{\mathrm{p}}} \mathrm{r}+\frac{\mathrm{UA}}{\rho \mathrm{c}_{\mathrm{p}} \mathrm{V}}\left(\mathrm{T}_{\mathrm{c}}-\mathrm{T}\right)+\frac{\mathrm{u}}{\mathrm{V}}\left(\mathrm{T}_{\mathrm{in}}-\mathrm{T}\right) \\
\\
\end{array}
$$

where $\mathrm{u}$ is the feed flow rate, $\mathrm{T}_{\text {in }}$ the inlet temperature, $\Delta \mathrm{H}$ the heat of reaction, $\rho$ the density, $c_{p}$ the heat capacity and $U$ the global heat transfer coefficient.

\subsection{Optimization problem}

The optimal control problem consists of minimizing the number of moles of $\mathrm{A}$ at the given final time $\mathrm{t}_{\mathrm{f}}$ by adjusting the feed flow rate $\mathrm{u}(\mathrm{t})$. In addition to the dynamic system equations (1)-(3), the following operational and safety constraints are present:

$$
\begin{aligned}
& \mathrm{u}_{\text {min }} \leq \mathrm{u} \leq \mathrm{u}_{\max } \\
& \mathrm{V} \leq \mathrm{V}_{\max }=\mathrm{V}_{\mathrm{a}}^{\circ}+\mathrm{V}_{\mathrm{b}}^{\circ} \\
& \mathrm{T}_{\mathrm{cf}}=\mathrm{T}+\min \left(\mathrm{N}_{\mathrm{a}}, \mathrm{N}_{\mathrm{b}}\right) \frac{(-\Delta \mathrm{H})}{\rho \mathrm{c}_{\mathrm{p}} \mathrm{V}} \leq \mathrm{T}_{\text {max }}
\end{aligned}
$$

$\mathrm{u}_{\min }$ and $\mathrm{u}_{\max }$ are the input bounds, and $\mathrm{V}_{\max }$ the maximum volume. Constraint (6) states that the temperature under cooling failure, $\mathrm{T}_{\mathrm{cf}}$, should not exceed the maximum temperature $\mathrm{T}_{\max }$. In case of a cooling failure, the system becomes adiabatic. The best strategy is to immediately stop the feed. Yet, due to the presence of unreacted components in the reactor, the reaction goes on. Thus, chemical heat will be produced, which causes an increase in temperature. The term $\min \left(\mathrm{N}_{\mathrm{a}}, \mathrm{N}_{\mathrm{b}}\right)$ serves to calculate the maximum extent of reaction that could occur following the failure, and $(-\Delta \mathrm{H}) / \rho \mathrm{c}_{\mathrm{p}} \mathrm{V}$ represents the adiabatic temperature rise. Hence, $\mathrm{T}_{\mathrm{cf}}$ represents the maximum attainable temperature.
The system will be studied in two operational modes: isoperibolic $\left(\mathrm{T}_{\mathrm{c}}=\right.$ constant $)$ and isothermal $(\mathrm{T}=$ constant $)$.

In isothermal operation, $\mathrm{T}$ is kept constant by adjusting $\mathrm{T}_{\mathrm{c}}$ as follows:

$$
T_{c}=T-\frac{(-\Delta H) V r}{U A}+\frac{u \rho c_{p}}{U A}\left(T-T_{\text {in }}\right)
$$

Eq. (7) can also be written as:

$$
(-\Delta H) V r+u \rho c_{p}\left(T_{\text {in }}-T\right)=U A\left(T-T_{c}\right)
$$

or

$$
\mathrm{Q}_{\mathrm{rx}} \quad+\quad \mathrm{Q}_{\mathrm{in}} \quad=\mathrm{Q}_{\mathrm{ex}}
$$

where $\mathrm{Q}_{\mathrm{rx}}$ is the heat produced by the chemical reaction, $\mathrm{Q}_{\text {in }}$ the relative heat added by the inlet stream, and $Q_{e x}$ the heat removed by the cooling jacket. The heat produced or added should not exceed the maximal heat removal capability, $\mathrm{Q}_{\text {ex,max }}$, that is obtained for the lowest possible value of $\mathrm{T}_{\mathrm{c}}$, $\mathrm{T}_{\mathrm{c}, \mathrm{min}}$ :

$$
\mathrm{Q}_{\mathrm{rx}}+\mathrm{Q}_{\mathrm{in}} \leq \mathrm{Q}_{\mathrm{ex}, \max }
$$

Isoperibolic operation $\left(\mathrm{T}_{\mathrm{c}}=\right.$ constant $)$

$$
\min _{u(t)} N_{a}\left(t_{f}\right)
$$

Subject to dynamic equations (1)-(3) algebraic constraints (4)-(6)

Isothermal operation $(\mathrm{T}=$ constant $)$

$\min _{\mathrm{u}(\mathrm{t})} \mathrm{N}_{\mathrm{a}}\left(\mathrm{t}_{\mathrm{f}}\right)$

Subject to

dynamic equations (1)-(2)

algebraic constraints (4)-(6) and (10)

\section{Numerical solution with PADPOS}

PADPOS [13] is a toolbox for MATLAB that has been written in house for dynamic optimization, i.e. for both parameter estimation and optimal control problems. The core idea is to convert the dynamic optimization problem into a standard nonlinear programming problem using (a) parameterization, and (b) time discretization [14]. The inputs and states are parameterized using piece-wise polynomials. The differential equations of the system are verified only at discrete collocation points. The resulting nonlinear program is solved using functions available in the optimization toolbox distributed with MATLAB. 


\subsection{Isoperibolic operation}

The optimal constant cooling temperature and the optimal feed rate profile are determined using PADPOS and the numerical values of system parameters and experimental conditions given in the Appendix. For this example with $\mathrm{T}_{\text {in }}=$ $\mathrm{T}_{\mathrm{c}}$, the optimal cooling temperature is $351 \mathrm{~K}$. For this temperature, the optimal input is given in Figure 1, and the corresponding temperature under cooling failure in Figure 2.

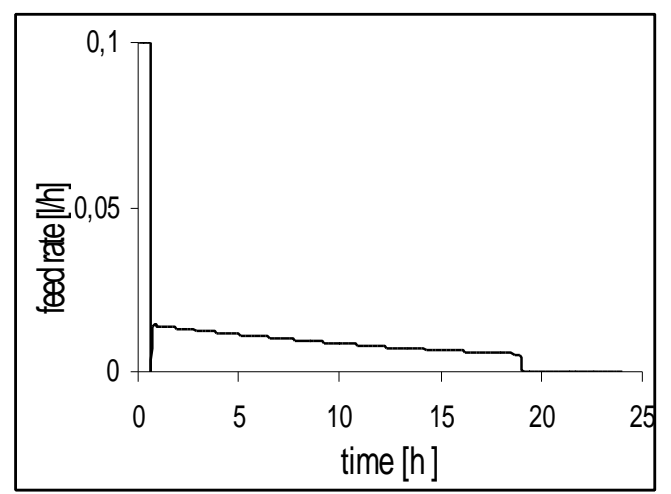

Fig. 1 Optimal feed rate

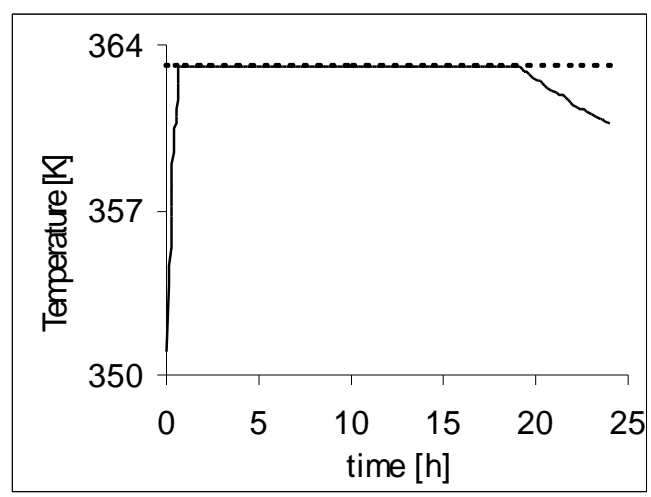

Fig. 2 Comparison of $\mathrm{T}_{\mathrm{cf}}$ (solid line) and $\mathrm{T}_{\max }$ (dash line)

First, reactant $\mathrm{B}$ is fed as quickly as possible until $\mathrm{T}_{\mathrm{cf}}=\mathrm{T}_{\max }$. Then, $\mathrm{u}$ is adjusted to maintain $\mathrm{T}_{\mathrm{cf}}$ constant. The constraint is not violated. Finally, when the constraint $\mathrm{V}=\mathrm{V}_{\max }$ becomes active, $\mathrm{u}=0$.

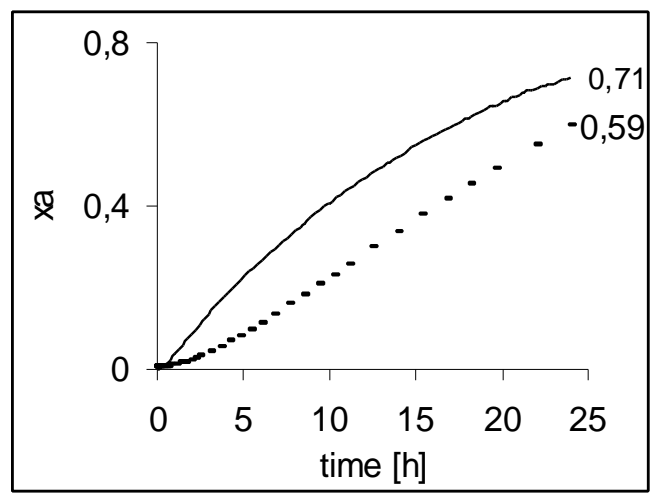

Fig. 3 Conversion with constant (dash line) and time-varying (solid line) input flow rates
Constant feed rates are common in industry. To appreciate how much can be gained using a time-varying input, the following comparison is made. The optimal constant input corresponds to $0.0093 \mathrm{l} / \mathrm{h}$ for the entire period. The conversions for the constant and time-varying optimal inputs are given in Figure 3. The curves indicate that about $20 \%$ more product can be obtained by using a time-varying input.

\subsection{Isothermal operation}

The optimal solution given by PADPOS for isothermal operation with $\mathrm{T}_{\mathrm{in}}=\mathrm{T}=350 \mathrm{~K}$ is depicted in Figure 4. The evolution of the temperature under cooling failure is given in Figure 5. The comparison of the heat produced $\mathrm{Q}_{\mathrm{rx}}$ and the maximum heat that can be removed $\mathrm{Q}_{\mathrm{ex}, \max }$ is presented in Figure 6.

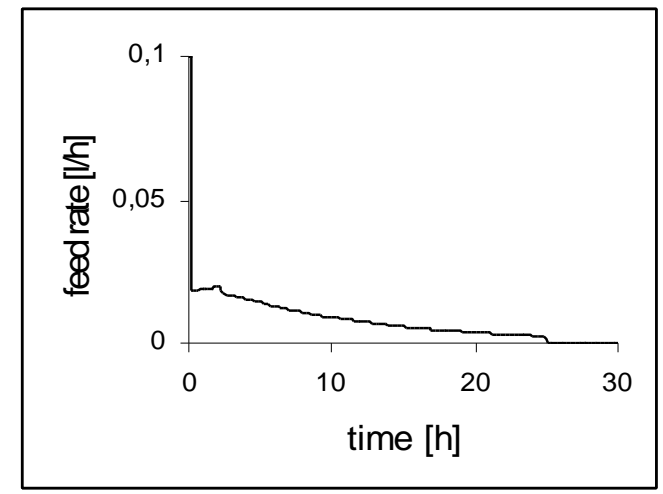

Fig. 4 Optimal feed rate

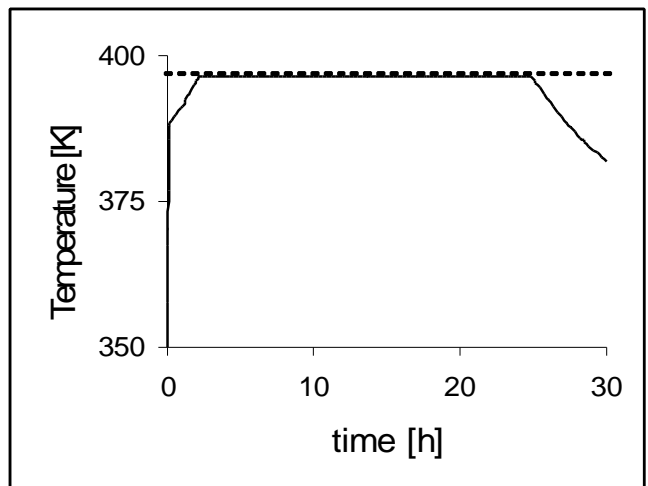

Fig. 5 Comparison of $\mathrm{T}_{\mathrm{cf}}$ (solid line) and $\mathrm{T}_{\max }$ (dash line)

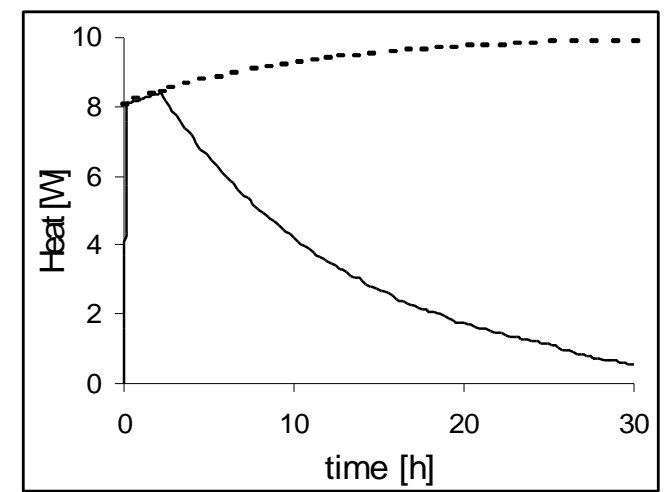

Fig. 6 Comparison of $\mathrm{Q}_{\mathrm{rx}}$ (solid line) and $\mathrm{Q}_{\mathrm{ex}, \max }($ dash line) 
First, the reactant $\mathrm{B}$ is fed with the maximum rate until $\mathrm{Q}_{\mathrm{rx}}=$ $Q_{\text {ex,max }}$. Then, $u$ is adjusted to ride on this constraint. However, the other constraint $\mathrm{T}_{\mathrm{cf}}=\mathrm{T}_{\max }$ becomes active after some time, and $\mathrm{u}$ is chosen in order to maintain this other constraint satisfied. Finally, when the volume reaches its maximum value $\mathrm{V}_{\max }$, $\mathrm{u}$ is set to zero.

As above, a comparison is made with the constant-input case. The optimal constant input corresponds to $0.00645 \mathrm{l} / \mathrm{h}$ for the entire period.

The conversions for the constant and time-varying optimal inputs are given in Figure 7. The curves indicate that about $20 \%$ more product can be obtained by using a time-varying input.

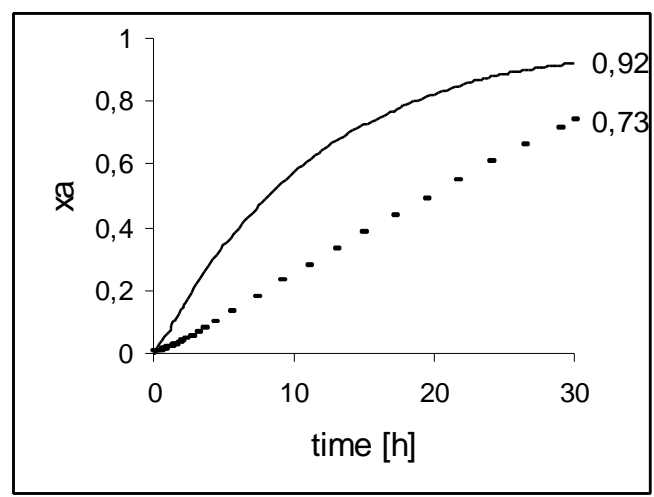

Fig. 7 Conversion with constant (dash line) and time-varying (solid line) input flow rates

\section{Characterization of the optimal solution}

\subsection{Isoperibolic operation $\left(T_{c}=\right.$ constant $)$}

From the numerical solution, one can formulate the nature of the generic solution (Figure 8) as follows:

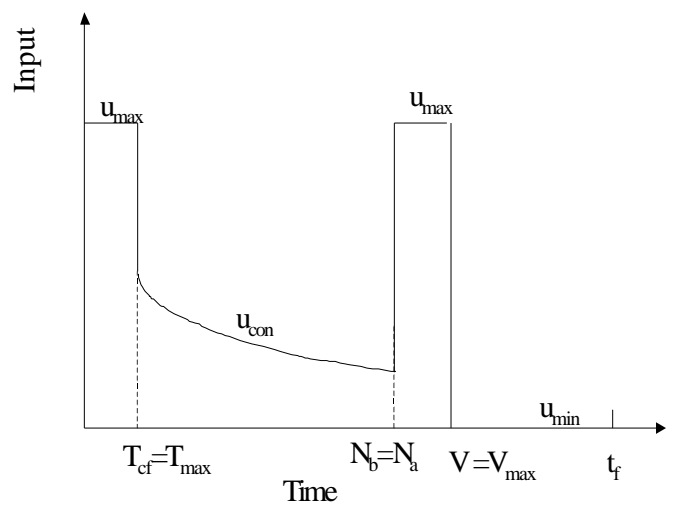

Fig.8 Input profile for isoperibolic operation

First, Reactant $\mathrm{B}$ is fed at maximum rate until $\mathrm{T}_{\mathrm{cf}}=\mathrm{T}_{\max }$.

Once the constraint is reached, the input is adjusted to maintain $\mathrm{T}_{\mathrm{cf}}$ constant. The value of the input which keeps the system on the safety constraint can be calculated from $\frac{\mathrm{d}}{\mathrm{dt}}\left(\mathrm{T}_{\mathrm{cf}}-\mathrm{T}_{\max }\right)=0$ and is given by:

$$
\mathrm{u}_{\text {con }}\left(\mathrm{x}_{\mathrm{a}}, \mathrm{V}, \mathrm{T}\right)=\frac{\frac{\mathrm{UA}}{\rho \mathrm{c}_{\mathrm{p}}}\left(\mathrm{T}-\mathrm{T}_{\mathrm{c}}\right)}{\left(\mathrm{T}_{\mathrm{in}}-\mathrm{T}\right)+\left(\frac{-\Delta \mathrm{H}}{\rho \mathrm{c}_{\mathrm{p}} \mathrm{V}}\right)\left(\frac{\mathrm{N}_{\mathrm{b}}^{\circ} \mathrm{V}_{\mathrm{a}}^{\circ}}{\mathrm{V}_{\mathrm{b}}^{\circ}}+\mathrm{N}_{\mathrm{a}}^{\circ} \mathrm{x}_{\mathrm{a}}\right)}
$$

As soon as there is a stoichiometric excess of $\mathrm{B}, \mathrm{N}_{\mathrm{a}}$ becomes smaller than $\mathrm{N}_{\mathrm{b}}$, and $\min \left(\mathrm{N}_{\mathrm{a}}, \mathrm{N}_{\mathrm{b}}\right)=\mathrm{N}_{\mathrm{a}}$. Addition of $\mathrm{B}$ does not have any effect on $T_{c f}$, and $u$ is set to $u_{\max }$ to maximize the conversion. Finally, when all B has been fed, the feed is stopped, and $\mathrm{u}=0$.

Thus, analytical expressions for the input between discontinuities and also for the switching conditions are available.

\subsection{Isothermal operation $(T=$ constant $)$}

Similar analytical expressions can be obtained for the isothermal case.

As illustrated in Figure 9, the reactant B is fed at maximum rate until one of the two path constraints becomes active. Then $\mathrm{u}$ is chosen equal to $\mathrm{u}_{\mathrm{con} 1}$ or $\mathrm{u}_{\mathrm{con} 2}$, depending on which of the two constraints is active. Switching between the constraints is also possible. In Figure 9, it is assumed that the second constraint (eq. 10) is active first and then the first constraint (eq. 6).

The input $\mathrm{u}_{\text {con1 }}$ makes the system ride on the first constraint and, from $\frac{\mathrm{d}}{\mathrm{dt}}\left(\mathrm{T}_{\mathrm{cf}}-\mathrm{T}_{\max }\right)=0$, is given by:

$$
\mathrm{u}_{\text {con } 1}\left(\mathrm{x}_{\mathrm{a}}, \mathrm{V}\right)=\frac{\mathrm{r} \mathrm{V}^{2}}{\frac{\mathrm{N}_{\mathrm{b}}^{\circ} \mathrm{V}_{\mathrm{a}}^{\circ}}{\mathrm{V}_{\mathrm{b}}^{\circ}}+\mathrm{N}_{\mathrm{a}}^{\circ} \mathrm{x}_{\mathrm{a}}}
$$

The input $\mathrm{u}_{\text {con } 2}$ keeps the second constraint active. For $\mathrm{Q}_{\text {in }}=0$ (i.e., $\mathrm{T}_{\mathrm{in}}=\mathrm{T}$ ), it is calculated from $\frac{\mathrm{d}}{\mathrm{dt}}\left(\mathrm{Q}_{\mathrm{rx}}-\mathrm{Q}_{\mathrm{ex}, \max }\right)=0$ :

$$
\mathrm{u}_{\operatorname{con} 2}\left(\mathrm{x}_{\mathrm{a}}, \mathrm{V}\right)=\frac{\mathrm{rV}^{2}\left(\mathrm{~N}_{\mathrm{b}}+\mathrm{N}_{\mathrm{a}}\right)}{\mathrm{N}_{\mathrm{a}}\left(\frac{\mathrm{N}_{\mathrm{b}}^{\circ} \mathrm{V}}{\mathrm{V}_{\mathrm{b}}^{\circ}}-\mathrm{N}_{\mathrm{b}}\right)-\frac{2 \mathrm{~V}^{2} \mathrm{U}\left(\mathrm{T}-\mathrm{T}_{\mathrm{c}}\right)}{\sigma \mathrm{k}^{\circ} \exp \left(\frac{-\mathrm{Ea}}{\mathrm{RT}}\right)(-\Delta \mathrm{H})}}
$$

The last part of the optimal solution is similar to that for the isoperibolic case. 


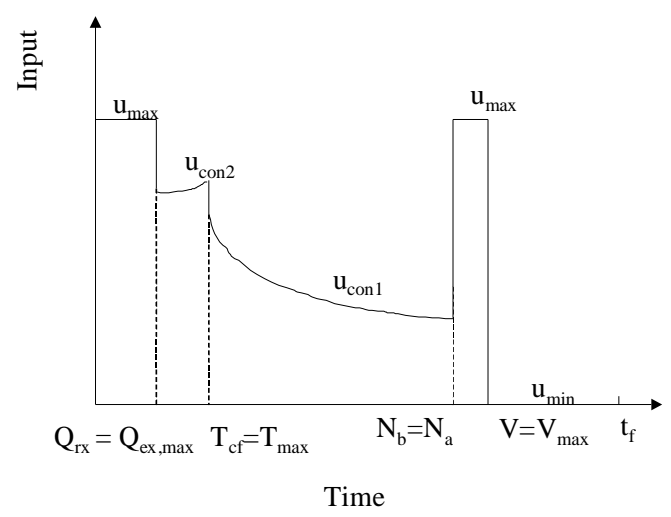

Fig. 9 Input profile for isothermal operation

\section{Implementation of the optimal solution}

In the implementation of the optimal solution, model uncertainties and disturbances (e.g. variations in initial conditions) should be taken into account. Yet, it is reasonable to assume that the characterization of the optimal trajectory described in Section 4 is still valid despite these variations.

There are 4 possible input characterization modes:

1. Input at its upper bound, $\mathrm{u}=\mathrm{u}_{\max }$.

2. Input at its lower bound, $\mathrm{u}=\mathrm{u}_{\min }$.

3. Input determined by $\mathrm{T}_{\mathrm{cf}}, \mathrm{u}=\mathrm{u}_{\mathrm{con} 1}$.

4. Input determined by heat removal, $\mathrm{u}=\mathrm{u}_{\mathrm{con} 2}$.

Modes 1 and 2 have to be executed in open loop, while a simple feedback controller can be used for the implementation of Modes 3 and 4.

The implementation schematic is shown in Figure 10. The block "construction of output" generates an output that represents the distance to the safety constraint for the actual input mode. The feedback controller then tracks a set point value of zero for the appropriate output. Analytical expressions for switching between the different modes are available, as can be seen in Figures 8 and 9. This is used for choosing the corresponding input mode.

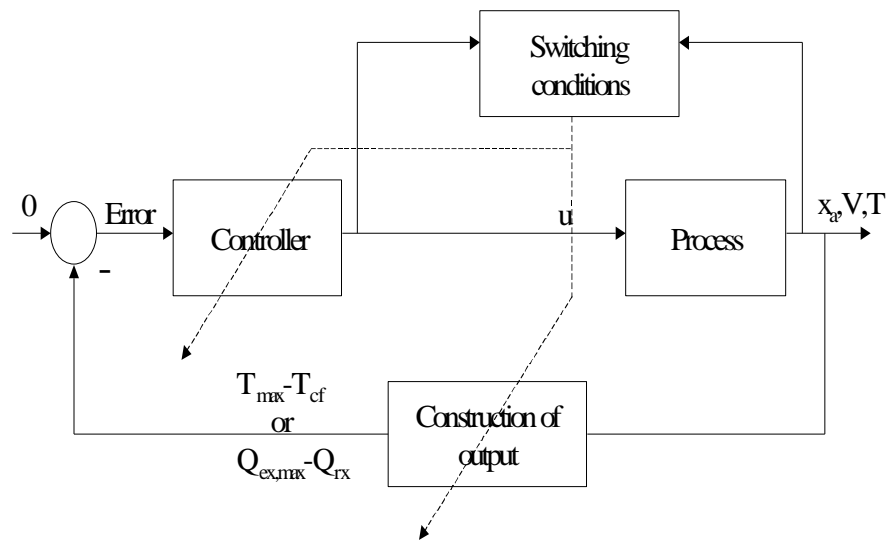

Fig. 10 Implementation schematic
Though, as described earlier, numerical optimization is necessary to compute the true optimum, a simple feedback controller can take the system relatively close to the optimum and, at the same time, provide additional robustness.

In practice, the true values of the process parameters are not known accurately. The implementation scheme discussed above provides an efficient way to handle such uncertainties. As an example, the isoperibolic operation with an error of $20 \%$ in $\mathrm{k}^{\circ}$ is considered $\left(\mathrm{k}^{\circ}=3.610^{3} \mathrm{~m}^{3} / \mathrm{mol} . \mathrm{s}\right)$. Figures 11 and 12 compare the open-loop application of the optimal input with the feedback strategy to track the constraint. Due to the error in $\mathrm{k}^{\circ}, \mathrm{T}_{\mathrm{cf}}$ is no longer at its maximum value when the "optimal" input is applied in an open-loop fashion. However, with the feedback strategy, $\mathrm{T}_{\mathrm{cf}}$ is closer to the constraint, thereby leading to an improved performance (5\% improvement).

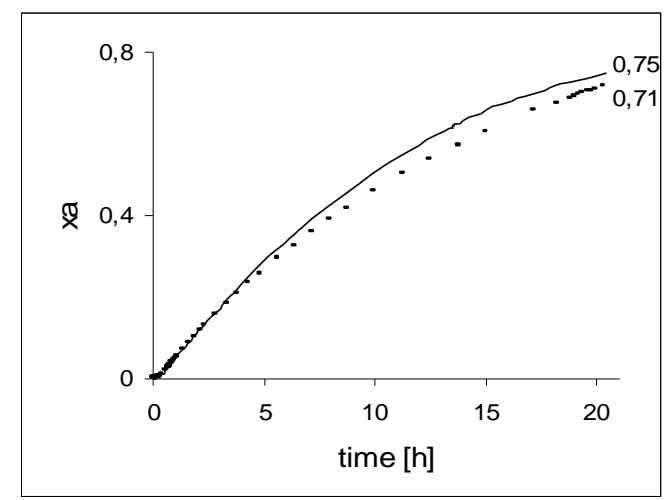

Figure 11 Comparison of conversions: open-loop (dash line) vs. closed-loop (solid line) implementations.

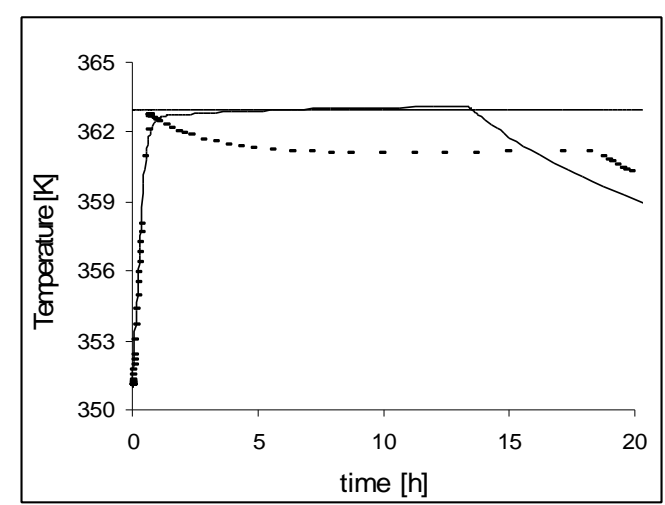

Figure 12 Comparison of $\mathrm{T}_{\mathrm{cf}}$ : open-loop (dash line) vs. closed-loop (solid line) implementations

\section{Conclusion}

This article discusses the optimization of a semi-batch reactor with safety constraints in both the isoperibolic and isothermal modes. Three interesting conclusions can be made:

- In the presence of safety constraints, semi-batch operation is preferred over batch operation. 
- Using a time-varying input instead of a constant input increases the yield significantly.

- The optimal solution can be easily implemented using a feedback strategy.

\section{Appendix}

A1 Numerical values of system parameters.

\begin{tabular}{|c|c|c|c|c|}
\hline Symbol & Description & Isoperibolic & Isothermal & Units \\
\hline$\Delta \mathrm{H}$ & $\begin{array}{c}\text { Reaction } \\
\text { enthalpy }\end{array}$ & -62000 & -162000 & {$[\mathrm{~J} / \mathrm{mol}]$} \\
\hline$\rho$ & Density & 900 & 900 & {$[\mathrm{~kg} / \mathrm{m} 3]$} \\
\hline $\mathrm{c}_{\mathrm{p}}$ & $\begin{array}{c}\text { Heat } \\
\text { capacity }\end{array}$ & 2000 & 2000 & {$[\mathrm{~J} / \mathrm{kg} . \mathrm{K}]$} \\
\hline $\mathrm{U}$ & $\begin{array}{c}\text { Heat } \\
\text { transfer } \\
\text { coefficient }\end{array}$ & 180 & 20 & {$[\mathrm{~W} / \mathrm{m} 2 . \mathrm{K}]$} \\
\hline $\mathrm{R}$ & $\begin{array}{c}\text { Radius of } \\
\text { reactor }\end{array}$ & 0.076 & 0.076 & {$[\mathrm{~m}]$} \\
\hline $\begin{array}{c}\text { Pre- } \\
\text { exponential } \\
\text { factor }\end{array}$ & $2.7810^{3}$ & $9.7210^{4}$ & {$[\mathrm{~m} 3 / \mathrm{mol} . \mathrm{s}]$} \\
\hline $\mathrm{Ea}$ & $\begin{array}{c}\text { Activation } \\
\text { energy }\end{array}$ & 72500 & 82500 & {$[\mathrm{~J} / \mathrm{mol}]$} \\
\hline
\end{tabular}

B1 Numerical values of experimental conditions.

\begin{tabular}{|c|c|c|c|}
\hline Symbol & Isoperibolic & Isothermal & Units \\
\hline $\mathrm{N}_{\mathrm{a}}^{\circ}$ & 0.5 & 2.5 & {$[\mathrm{~mol}]$} \\
\hline $\mathrm{N}_{\mathrm{b}}^{\circ}$ & 0.5 & 2.5 & {$[\mathrm{~mol}]$} \\
\hline $\mathrm{V}_{\mathrm{a}}^{\circ}$ & 0.32 & 0.32 & {$[\mathrm{l}]$} \\
\hline $\mathrm{V}_{\mathrm{b}}^{\circ}$ & 0.23 & 0.23 & {$[1]$} \\
\hline $\mathrm{T}_{\max }$ & 363 & 397 & {$[\mathrm{~K}]$} \\
\hline $\mathrm{t}_{\mathrm{f}}$ & 24 & 30 & {$[\mathrm{~h}]$} \\
\hline $\mathrm{u}_{\min }$ & 0 & 0 & {$[1 / \mathrm{h}]$} \\
\hline $\mathrm{u}_{\max }$ & 0.1 & 0.1 & {$[\mathrm{l} / \mathrm{h}]$} \\
\hline $\mathrm{T}_{\mathrm{in}}$ & 351 & 350 & {$[\mathrm{~K}]$} \\
\hline $\mathrm{T}_{\mathrm{c}, \min }$ & - & 335 & {$[\mathrm{~K}]$} \\
\hline $\mathrm{T}$ & - & 350 & {$[\mathrm{~K}]$} \\
\hline $\mathrm{T}_{\mathrm{c}}$ & 351 & - & {$[\mathrm{K}]$} \\
\hline
\end{tabular}

\section{Acknowledgement}

This work is a part of the $\mathrm{PhD}$ thesis prepared by O. Ubrich at the EPFL with a financial support from the Corporate Heath, Safety and Environment of Novartis AG (Basel). Dr. Eigenmann, head of this department, is especially thanked.

\section{References}

[1] Semenov, N. N. Zur Theorie des Verbrennungsprozesses. Z. Phys. Vol. 48, pp. 571-581, (1928).

[2] Gygax, R., Chemical reaction engineering for safety, Chem. Eng. Sci., Vol. 43, n8, pp. 1759-1771, (1988).

[3] Hugo, P., Steinbach, J., Practically oriented representation of safe limits for an indirectly cooled semi batch reactors. Chem. Ing. Tech. 57, pp. 780-782, (1985).

[4] Strozzi, F., Zaldìvar, J.M., Westerterp, K. R., Runaway prevention in chemical reactors using chaos theory techniques. Joint research center, Report EUR 17696, (1997).

[5] Garcia, V., Exploitation des modèles de tendances stœchiométriques et cinétiques pour l'optimisation des réacteurs discontinus de chimie fine. Thèse de doctorat $\mathrm{n}^{\circ}$ 757-INP Toulouse, (1993).

[6] Filippi, C., Greffe, J. L., Bordet, J., Villermaux, J., Barnay, J. L., Bonte, P., Georgakis, C., Tendency modeling of semi-batch reactors for optimization and control. Chem. Eng. Sci., Vol. 41, n4, pp. 913-920, (1986).

[7] Marchal-Brassely, S., Villermaux, J., Houzelot, J. L., Barnay, J. L., Optimal operation of a semi batch reactor by self-adaptive models for temperature and feedate profiles. Chem. Eng. Sci., Vol. 47, n $9-11$, pp. 24452450, (1992).

[8] Lerena, P., Wehner, W., Weber, H., Stoessel. F., Assessment of hazards linked to accumulation in semibatch reactors. Thermochimica Acta. 289, 127-142, 1996).

[9] Abel, O., Helbig, A., Marquardt, W., Optimization approaches to control-integrated design of industrial batch reactors, In R. Berber, editor, Nonlinear Model Based Process Control, NATO-ASI Series, pp. 512-552, Kluwer Press, The Netherland 1998)

[10] Abel, O., Marquardt, W., A model predictive control scheme for safe and optimal operation of exothermic semi-batch reactors, IFAC Symposium DYCOPS-5, Corfu, pp. 761-766 (1998).

[11] Matlab 5.1., The MathWorks, Inc, (1997).

[12] Srinivasan, B., Visser, E., Bonvin, D., Optimizationbased control with imposed feedback structures. Proceedings ADCHEM'97, pp. 635-640, Banff, (1997).

[13] PADPOS, User's manual. Institut d'Automatique, EPFL, Lausanne, Switzerland, (1998).

[14] Tjao, I. B., Biegler, L. T., Simultaneous solution and optimization strategies for parameter estimation of differential-algebraic equation systems. Ind. Eng. Chem. Res. pp. 376-385 (1991). 